\title{
Effect of Pronated Foot Posture on the Arabic Version of WOMAC Index in Women with Medial Compartment Knee Osteoarthritis
}

\author{
AALAA M. SWEELAM, M.Sc.*; SALWA F. ABD EL-MAGEED, Ph.D.**; \\ EBTESSAM F. GOMAA, Ph.D.** and AHMAD H. AZZAM, M.D.*** \\ The Department of Physical Therapy, General Administration of Medical Affairs Hospital, Menoufia University*, \\ The Department of Physical Therapy for Musculoskeletal Disorders \& their Surgeries, Faculty of Physical Therapy** and \\ The Department of Orthopedic Surgery, Faculty of Medicine***, Cairo University, Cairo, Egypt
}

\begin{abstract}
Background: Knee Osteoarthritis (KOA) is one of the most common musculoskeletal conditions affecting old population and is rated as the 4 th suspected cause of disability by year 2020. Recent studies have reported difference in foot characteristics between people with medial compartment KOA and asymptomatic controls, indicating a more pronated foot posture in those with OA. Abnormal feet position is associated with altered lower extremity functional and muscle activation patterns.
\end{abstract}

Aim of the Study: To investigate the effect of pronated foot posture on the Arabic Version of WOMAC index in women with knee osteoarthritis.

Patients and Methods: Sixty six female patients with mean ages (61.66 \pm 5.77$)$ years and body mass index $(28.71 \pm$ 1.16) $\mathrm{Kg} / \mathrm{m}$ with primary knee osteoarthritis grade II, III only with a radiographic and diagnostic criterion knee pain participated in this study. Foot posture assessment was done first to categorize them into 3 groups (normal, pronated and supinated) feet using foot posture index. Group (A) normal foot consisted of 24 participants. Group (B) pronated foot consisted of 24 participants. Group (C) supinated foot consisted of 18 participants; knee function assessment was done by using the Arabic version of WOMAC index.

Results: The results demonstrated that that there was significant difference between (Group B (pronated) Vs. Group $\mathrm{C}$ (supinated)) with significant increase in ArWOMAC subscale for physical function in favor to Group B (pronated) while no significant difference was found in the other two subscales (pain and stiffness)of the ArWOMAC index $(\mathrm{F}=1.368, p=$ $0.203)$.

Conclusion: It can be concluded that there was a significant effect of pronated foot posture on physical function subscale of ArWOMAC index in KOA, while all other foot postures don't affect pain, stiffness or physical function subscales of ArWOMAC index in patients with KOA.

Correspondence to: Dr. Aalaa M. Sweelam, E-Mail: amsweelam@hotmail.com
Key Words: Knee osteoarthritis - Medial compartment knee osteoarthritis - Foot posture - Knee function Questionnaires - ArWOMAC index.

\section{Introduction}

OSTEOARTHRITIS of the knee is the most common form of arthritis and leads to more activity limitations (e.g., disability in walking and stair climbing) than any other disease especially in the elderly [1].

Foot posture has been suggested to be related to the development of lower-limb musculoskeletal conditions [2] because of its potential influence on the mechanical alignment and dynamic function of the lower limb [3]. Biomechanical evidence also supports the notion that feet with extremes of foot posture (i.e., planus or cavus) or foot posture (i.e., overpronated or oversupinated) are associated with altered lower extremity functional alignment [4] and muscle activation patterns [5]. Higher prevalence of pronated foot posture and alterations in plantar distribution in knee OA has been revealed in a study [6].

Studies have reported differences in foot characteristics between people with medial compartment knee OA and asymptomatic controls $[7,8]$. There is limited research on female foot posture, there is an even smaller amount of research on foot posture and its relationship with knee injury; therefore there is a need for additional examination [9]. Additionally, abnormal motion of the foot has also been proposed to lead to greater stress on more proximal structures such as the knee joint due to coupling between the foot and the knee [4] . 


\section{Aim of the study:}

To investigate the effect of foot posture on knee function in knee osteoarthritis' female patients by a valid and reliable tool (ArWOMAC).

\section{Patients and Methods}

This study was an observational case-control study was designed to investigate the effect of foot posture (using foot posture index) on knee function (using ArWOMAC index) in women with knee osteoarthritis. It was applied in the General Administration of Medical Affairs Hospital, Menofia University; Egypt. Informed consent was obtained from each patient before enrollment in the study. The study have been approved by Ethical Committee of Faculty of Physical Therapy, Cairo University with number 012/001618 in 30 April 2017.

\section{Inclusion and exclusion criteria:}

Sixty six female patients with primary KOA grade II, III only with a radiographic and diagnostic criterion knee pain for most days of prior month, osteophytes at joint margins (radiograph), synovial fluid typical of OA (laboratory), age $\geq 40$, morning stiffness $\leq 30$ minutes, crepitus on active joint motion according to American College of Rheumatology (ACR) [10] were included with mean ages (61.66 \pm 5.77$)$; ACR clinical and radiographic criteria. Firstly assessing every patient weight and height by using the scale and tape measurement respectively and measuring BMI only values between $25-30 \mathrm{Kg} / \mathrm{m}^{2}$ was included. Any patient with surgical intervention in the knee and/or hip, any previous fracture in the lower limbs, malignancy, any ligamentous injuries in knee or ankle, spinal cord injury, hormonal imbalance or on hormonal therapy, back problems, using corticosteroids, muscle relaxants or sedatives, knee injection therapy in previous 6 months, physical therapy at last 6 months, using assistive devices, visual or vestibular system problems that could affect the patient's balance were excluded.

Secondly foot posture assessment by scoring each of six criteria (Appendix I) according to observation and palpation then total number were summed to categorize patient's foot posture into 3 groups [normal (A) $\mathrm{N}=24$, pronated (B) $\mathrm{N}=24$ and supinated (C) $\mathrm{N}=18$ ] feet. It was used to assess foot posture supported by researchers as they mentioned that it is considered a novel, valuable and reliable diagnostic clinical tool to quantify positional variations of the foot, it measures foot posture in three planes and two anatomical segments and take into consideration six assessment criteria [11], agreed by a statement that it is an easy tool yielding quantifiable data with good face validity and can be performed with no special equipment [12]. Moreover it is considered a simple and rapid method and has demonstrated good reliability [13] .

Then as an inclusion criterion an examination of the flexibility of flatfoot was done by asking each patient to stand on tiptoes and observe flexible and rigid flatfoot; where flexible flat foot was included, while static (rigid) flat foot was excluded.

For knee function assessment; the Arabic version of WOMAC index (Appendix II) was used for every patient in each group for measuring lower limb functional disability supported by a conclusion that the ArWOMAC index is a reliable and valid instrument for evaluating the severity of knee OA, with metric properties in agreement with the original version [14]

\section{Statistical analysis:}

Prior to final analysis, data were screened for normality assumption, homogeneity of variance using Shapiro-Wilk test showed that WOMAC for pain, WOMAC for physical function were normally distributed and not violates the parametric assumption.

Additionally, testing for the homogeneity of covariance revealed that there was no significant difference with $p$-values of $>0.05$. However, the homogeneity of variance test and test of normality using Shapiro-Wilk test were significant in one variable only (WOMAC for stiffness) with the $p=$ 0.004. Data transformation (using the logarithm) was conducted. After data transformation, the normality and homogeneity of variance assumptions still violated the parametric tests for WOMAC for stiffness.

Parametric analysis for WOMAC for pain and WOMAC for physical function, while nonparametric analysis for WOMAC for stiffness was conducted. One way MANOVA was used to compare the tested variables of interest (WOMAC for pain and WOMAC for physical function) at different tested groups. While Kruskal-Wallis H-test (nonparametric alternative to the one-way ANOVA and an extension of the Mann-Whitney U-test) was used to compare the WOMAC for stiffness among three groups and "Mann-Whitney tests" was used as post hoc tests if Kruskal-Wallis H-test among three groups is significant. As two statistical analysis tests (one way MANOVA and Kruskal-Wallis H-test) were performed on the examined sample, the alpha level was adjusted to $0.025(0.05 / 2)$ for 
each of the two conducted statistical tests. Adjustment was performed to avoid alpha inflation and committing type I error.

\section{Results}

Participants were assigned into three studies groups. Group (A) N=24 participants with mean age and BMI values of $61.79 \pm 5.97$ years and $28.71 \pm$ $1.16 \mathrm{Kg} / \mathrm{m}^{2}$ respectively. Group (B) $\mathrm{N}=24$ participants with mean age and BMI values of $62.58 \pm 6.07$ years and $28.59 \pm 0.97 \mathrm{Kg} / \mathrm{m}^{2}$ respectively. Group (C) $\mathrm{N}=18$ participants with mean age and BMI values of $60.27 \pm 5.10$ years and $28.19 \pm 1.54 \mathrm{Kg} / \mathrm{m}^{2}$ respectively. As indicated by the One Way Analysis of Variance (ANOVA), there were no significant differences $(p>0.05)$ in the mean values of age and BMI among the three tested groups (Table 1).

\section{1- WOMAC for physical function:}

As presented in (Table 2), the mean \pm SD values of WOMAC for function in the "Group A", "Group B", and "Group C" were 21.2 $\pm 8.79,25.54 \pm 8.93$, and $17.05 \pm 8.15$ respectively. The multivariate test revealed that there was significant difference in the mean values of WOMAC for physical function among three groups $(p=0.01)$. As well as, multiple pairwise comparison tests (post hoc tests) revealed that there was significant difference between (Group B Vs. Group C) with $(p=0.008$ ) and this significant increase in WOMAC for function in favor to Group B. While, there were no significant differences between (Group A Vs. Group B) and (Group A Vs. Group C) with $(p=0.266,0.39)$ respectively.

\section{2- WOMAC for pain:}

As presented in (Table 3 ), the mean \pm SD values of WOMAC for pain in the "Group A", "Group B", and "Group C" were 6.20 $\pm 3.28,8.2 \pm 3.34$, and $6.05 \pm 3.81$ respectively. The multivariate test revealed that there was no significant difference in the mean values of WOMAC for pain among three groups $(p=0.073)$.

\section{3- WOMAC for stiffness:}

As presented in (Table 4), the median (IQR) values of WOMAC for stiffness in the "Group A", "Group B", and "Group C" were 2 (3), 1.5 (3.75), and 0.5 (2.25) respectively. The" Kruskal-Wallis H-test" revealed that there was no significant difference in the median values of WOMAC for stiffness among three groups $(\chi=0.32$ and $p=$ 0.572 ).

Table (1): Descriptive statistics and One Way Analysis of Variance (ANOVA) for the mean age and BMI values for the three tested groups.

\begin{tabular}{lcccccc}
\hline & $\begin{array}{c}\text { Group A } \\
(\mathrm{N}=24)\end{array}$ & $\begin{array}{c}\text { Group B } \\
(\mathrm{N}=24)\end{array}$ & $\begin{array}{c}\text { Group C } \\
(\mathrm{N}=18)\end{array}$ & $\begin{array}{c}\mathrm{F}- \\
\text { value }\end{array}$ & $\begin{array}{c}p- \\
\text { value }\end{array}$ & $\begin{array}{c}\text { Level of } \\
\text { significant }\end{array}$ \\
\hline Age (years) & $61.79 \pm 5.97$ & $62.58 \pm 6.07$ & $60.27 \pm 5.10$ & 0.824 & 0.443 & N.S \\
BMI $(\mathrm{kg} / \mathrm{m})$ & $28.71 \pm 1.16$ & $28.59 \pm 0.97$ & $28.19 \pm 1.54$ & 1.005 & 0.372 & N.S \\
\hline
\end{tabular}

*: Significant at $p$-value $<0.05$.

Table (2): Descriptive statistics and one way MANOVA for WOMAC for physical function among different groups.

\begin{tabular}{lccccc}
\hline Mean \pm SD & Group A & Group B & Group C F-value & $p$-value \\
\hline WOMAC for physical function & $21.5 \pm 8.79$ & $25.54 \pm 8.93$ & $17.05 \pm 8.15$ & 4.965 & 0.01 \\
\hline \multicolumn{2}{r}{ Post hoc tests for the } & WOMAC for function among different groups & \\
\hline WOMAC for physical function & Group A & Group B & Group C \\
\hline Group A & & - & - \\
Group B & 0.266 & & - \\
Group C & 0.39 & $0.008^{*}$ & - \\
\hline
\end{tabular}

*: Significant at $p$-value $<0.025$.

Table (3): Descriptive statistics and one way MANOVA for WOMAC for pain among different groups.

\begin{tabular}{lccccc}
\hline Mean \pm SD & Group A & Group B & Group C & F-value & $p$-value \\
\hline WOMAC for pain & $6.20 \pm 3.28$ & $8.2 \pm 3.34$ & $6.05 \pm 3.81$ & 2.736 & 0.073 \\
\hline
\end{tabular}


Table (4): Descriptive statistics and Kruskal-Wallis H-test of the WOMAC for stiffness among different groups.

\begin{tabular}{lccccc}
\hline Median (IQR) & Group A & Group B & Group C & $\mathrm{X}^{2}$-value & $p$-value \\
\hline WOMAC for stiffness & $2(3)$ & $1.5(3.75)$ & $0.5(2.25)$ & 0.32 & 0.572 \\
\hline$* \quad:$ Significant at $p$-value $<0.025$. & & & & \\
IQR : Interquartile Range. &
\end{tabular}

\section{Discussion}

A study's conclusion by Rodriguez et al., 2013 [15] supported the gender selection but in healthy population as they concluded in their study that the most frequent posture was neutral with a certain degree of pronation, with no differences in FPI values between men and women; moreover mentioned in their results that greater proportion of women had neutral and pronated feet and a greater proportion of men had supinated and highly supinated feet, with the differences being no significant. Another study supported the population found in our study but in young players by confirming a tendency towards normal feet as being pronated rather than 'neutral' [21]. Also normative data for the FPI obtained from 619 healthy adults has been presented and compared with grouped data from 1,029 further observations; based on the analyses presented, it was concluded that foot posture was influenced by age and presence of pathology, but is not influenced by sex or BMI [25]. Furthermore Teyhen et al., [26] reported a similar percentage of neutral feet as Rodriguez et al., [15] study but a higher proportion of pronated feet and a lower proportion of supinated feet.

The current study support the correlation between foot posture and lower limb osteoarthritis as concluded by Hillstrom et al., [16]. Also, it comes in line with Levinger et al., [8] in which they compared the FPI between knee OA and controls. They don't found any difference in navicular height between the two groups, however pronated foot type was noted in the knee OA group compared to controls so they concluded that people with medial compartment knee OA exhibit a more pronated foot type compared to controls. Gross et al., reported an association between flat foot morphology and knee pain and medial tibio-femoral cartilage damage, which agrees with our findings [24].

A study by Abourazzak et al., [17] revealed that pronated foot posture and flat foot are significantly associated with medial compartment knee osteoarthritis in Moroccan people. Moreover abnormal foot posture was found in another study of people with severe knee medial compartment OA; authors reported a significantly higher median score in those with knee OA, indicative of a more pronated foot posture [7].

Also Reilly et al., assessed the foot type of three groups medial compartment knee osteoarthritis, hip osteoarthritis, and healthy age matched controls; this study showed significant difference between groups concerning ankle dorsiflexion and arches, they concluded that people with medial compartment knee OA had a normal ankle dorsiflexion and more pronated foot type as indicated by the FPI [22], a study of U.S. Marine recruits found that flat or pronated feet were found to be associated with shin splints or knee pain [23]. Our findings in the study also support a statement that variations in foot posture are thought to influence the function of lower limb [12]

The findings of the current study showed a significant effect of pronated foot on ArWOMAC physical function subscale which come in line with Menz et al., [18] question whether foot posture is associated with falls in older people and Scott et al., [19] assumption that it can be a tool for assessing age-related differences in foot structure. Furthermore AlAbdulwahab and Kachanathu 2016 [20] concluded that higher degrees of FPI might have an effect on standing dynamic balance in healthy subjects.

On the other hand a study found that patients with knee osteoarthritis have no correlation between foot and knee Posture characteristics [27].

The results of the current study offered the need for considering exercises, wedge insole or silicone gel arch for flatfoot treatment in knee osteoarthritis patients and normalizing foot posture should be considered a necessity for maintaining optimal mechanics and injury prevention.

\section{Conclusion:}

According to the results, it can be concluded that there is a significant effect of pronated foot posture on ArWOMAC physical function subscale while no significant effect was found in the other two subscales (pain and stiffness) of the ArWOMAC index. Also there was no significant effect of other foot postures on knee function in women with KOA. 


\section{References}

1- GUCCIONE A., FELSON D., ANDERSON J., ANTHONY J., ZHANG Y., WILSON P., KELLY-HAYES M., WOLF P., KREGER B. and KANNEL W.: The effects of specific medical conditions on the functional limitations of elders in the Framingham Study. American Journal of Public Health, 84 (3): 351-58, 1994.

2- DONATELLI R.: Abnormal biomechanics of the foot and ankle. Journal of Orthopaedic \& Sports Physical Therapy, 9 (1): 11-6, 1987.

3- GUICHET J., JAVED A., RUSSELL J. and SALEH M. Effect of the foot on the mechanical alignment of the lower limbs Clinical orthopaedics and related research, 415: 193-201, 2003.

4- WILLIAMS D., MCCLAY I. and HAMILL J.: Arch structure and injury patterns in runners. Clinical Biomechanics (Bristol, Avon), 16 (4): 341-47, 2001.

5- WILLIAMS D., DAVIS I., SCHOLZ J., HAMILL J. and BUCHANAN T.S.: High-arched runners' exhibit increased leg stiffness compared to low-arched runners. Gait Posture, 19 (3): 163-69, 2004.

6- ROSLAND T., GREGERSEN L., ESKEHAVE T., KERSTING U. and ARENDT-NIELSEN L.: Pain sensitization and degenerative changes are associated with aberrant plantar loading in patients with painful knee osteoarthritis. Scandinavian Journal of Rheumatology, 44 (1): 61-9, 2015.

7- REILLY K., BARKER K., SHAMLEY D., NEWMAN M., OSKROCHI G. and SANDALL S.: The role of foot and ankle assessment of patients with lower limb osteoarthritis. Physiotherapy, 95 (3): 164-69, 2009.

8- LEVINGER P., MENZ H., FOTOOHABADI M., FELLER J., BARTLETT J. and BERGMAN N.: Foot posture in people with medial compartment knee osteoarthritis. Journal of Foot and Ankle Research, 6 (1): 1, 2010.

9- BROWN E.: An investigation into the relationship between foot posture and knee (Doctoral dissertation, Cardiff Metropolitan University), 2014.

10-ALTMAN R., ALARCON G., APPELROUTH D., BLOCH D., BORENSTEIN D., BRANDT K., BROWN C., COOKE T., DANIEL W., FELDMAN D. and GREENWALD R.: The American College of Rheumatology criteria for the classification and reporting of osteoarthritis of the hip. Arthritis \& Rheumatism, 34 (5): 505-14, 1991.

11- ALABDULWAHAB S. and KACHANATHU S.: Effects of body mass index on foot posture alignment and core stability in a healthy adult population. Journal of Exercise Rehabilitation, 12 (3): 182, 2016.

12- TELEGBA S.: Static Foot Posture-Predictor of Dynamic Foot Motion. Journal of Novel Physiotherapies, 5: 272, 2015.

13- MORRISON S. and FERRARI J.: Inter-rater reliability of the Foot Posture Index (FPI-6) in the assessment of the paediatric foot. Journal of Foot and Ankle Research, 2 (1): 1, 2009.

14- ALGHADIR A., ANWER S., IQBAL Z. and ALSANAWI H.: Cross-cultural adaptation, reliability and validity of the Arabic version of the reduced Western Ontario and
McMaster Universities Osteoarthritis index in patients with knee osteoarthritis. Disability and rehabilitation, 38 (7): 689-94, 2016.

15- RODRÍGUEZ R., NOVA A., MARTÍNEZ E., MARTÍN B., QUINTANA R. and ZAMORANO J.: The foot posture index: anthropometric determinants and influence of sex. Journal of the American Podiatric Medical Association, 103 (5): 400-4, 2013.

16- HILLSTROM H., BROWER D., WHITNEY K., McGUIRE J. and SCHUMACHER H.: Lower extremity conservative realignment therapies for knee osteoarthritis. Philadelphia: Hanley and Belfus. Physical Medicine and Rehabilitation, 16 (3): 507, 2002.

17- ABOURAZZAK F., KADI N., AZZOUZI H., LAZRAK F., NAJDI A., NEJJARI C. and HARZY T.: A Positive Association between Foot Posture Index and Medial Compartment Knee Osteoarthritis in Moroccan People. The Open Rheumatology Journal, 8: 96, 2014.

18- MENZ H., MORRIS M. and LORD S.: Foot and ankle risk factors for falls in older people: A prospective study. The Journals of Gerontology Series A: Biological Sciences and Medical Sciences, 61 (8): 866-70, 2006.

19- SCOTT G., MENZ H. and NEWCOMBE L.: Age-related differences in foot structure and function. Gait \& Posture, 26 (1): 68-75, 2007.

20- ALABDULWAHAB S. and KACHANATHU S.: Effects of body mass index on foot posture alignment and core stability in a healthy adult population. Journal of Exercise Rehabilitation, 12 (3): 182, 2016.

21- CAIN L., NICHOLSON L., ADAMS R. and BURNS J.: Foot morphology and foot/ankle injury in indoor football. Journal of Science and Medicine in Sport, 10 (5): 311 19, 2007.

22- REILLY K., BARKER K., SHAMLEY D. and SANDALL S.: Influence of foot characteristics on the site of lower limb osteoarthritis. Foot Ankle International, 27: 206-11, 2006.

23- KAUFMAN K., BRODINE S., SHAFFER R., JOHNSON C. and CULLISON T.: The effect of foot structure and range of motion on musculoskeletal overuse injuries. American Journal for Sports Medicine, 27: 585-93, 1999.

24- GROSS K., FELSON D., NIU J., HUNTER D., GUERMAZI A., ROEMER F., DUFOUR A., GENSURE R. and HANNAN M.: Association of flat feet with knee pain and cartilage damage in older adults. Arthritis Care \& Research, 63 (7): 937-44, 2011.

25- REDMOND A., CRANE Y. and MENZ H.: Normative values for the foot posture index. Journal of Foot and Ankle Research, 1 (1): 6, 2008.

26- TEYHEN D., STOLTENBERG B., ECKARD T., DOYLE P., BOLAND D., FELDTMANN J., MCPOIL T., CHRISTIE D., MOLLOY J. and GOFFAR S.: Static foot posture associated with dynamic plantar pressure parameters. Journal of Orthopaedic \& Sports Physical Therapy, 41 (2): 100-7, 2011.

27- KIM S., KIM S. and KIM H.: The correlation between foot and knee posture characteristics in knee osteoarthritis people. Journal of the Korean Society of Physical Medicine, 7 (4): 433-42, 2012. 


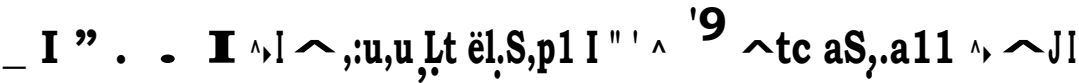

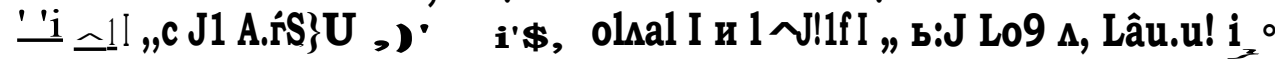

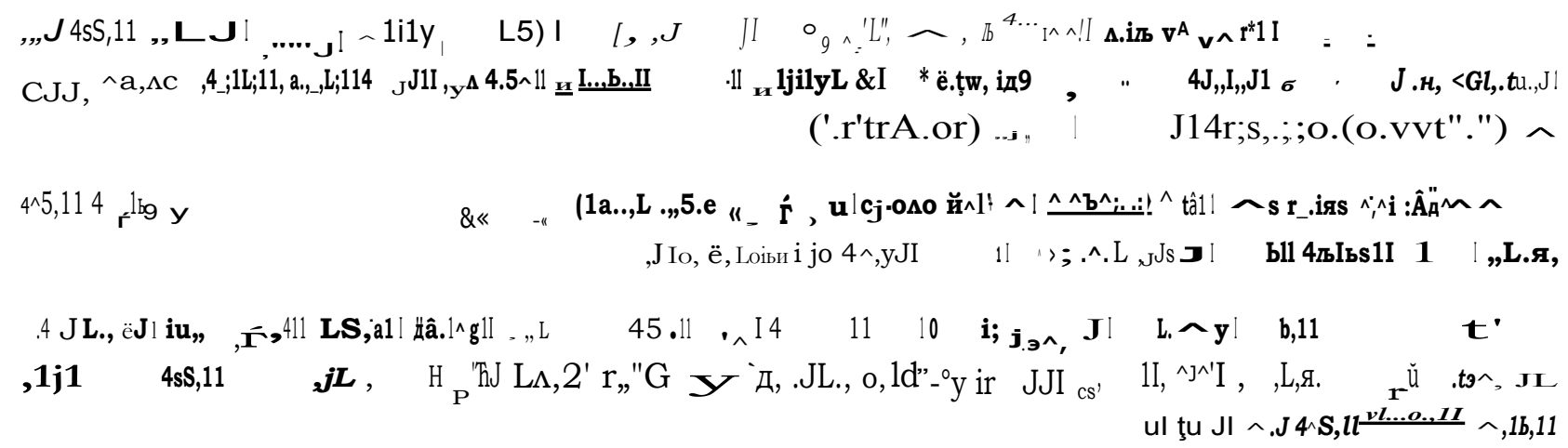

\section{Appendix I}

Foot Posture Index Datasheet

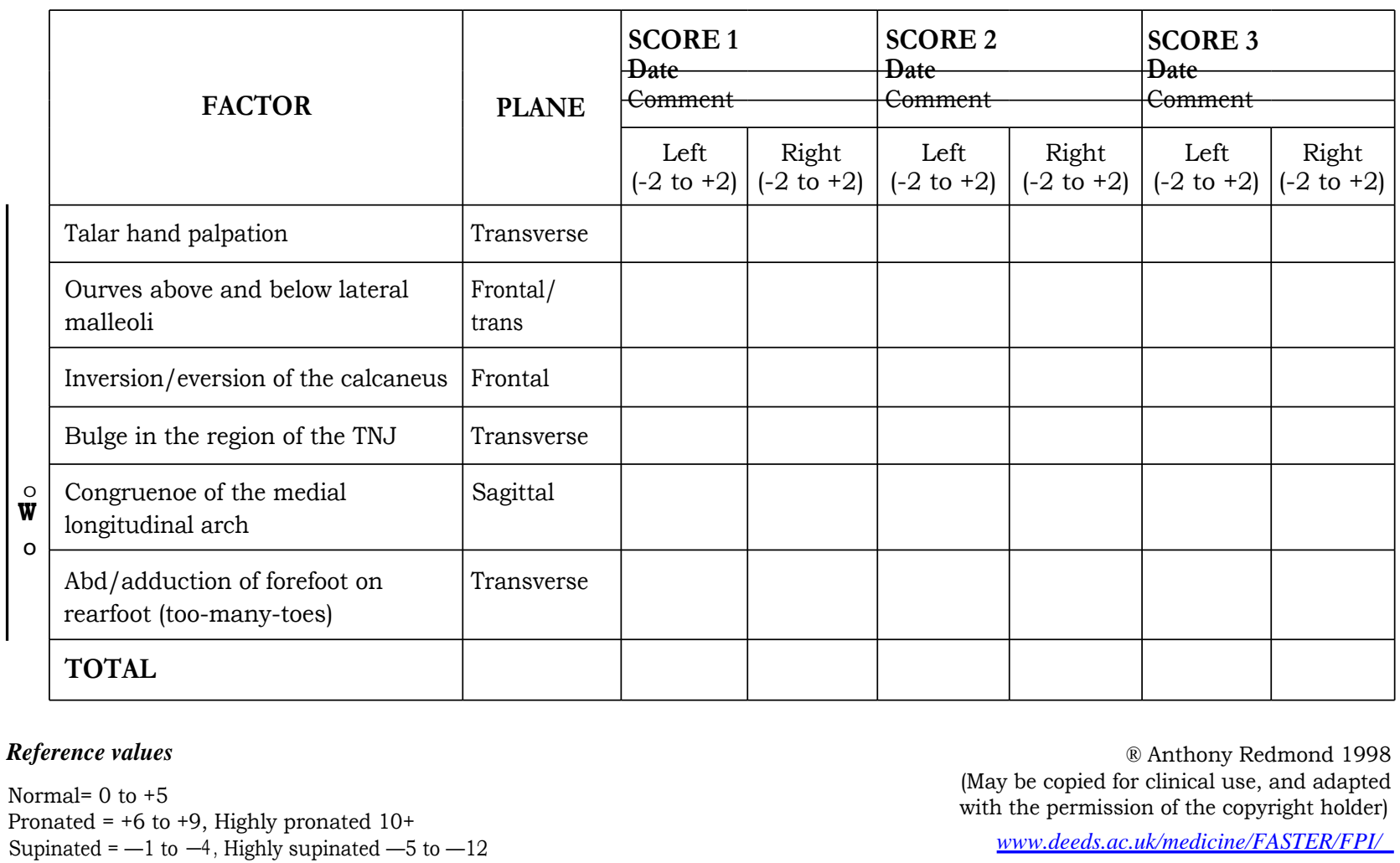




\section{Appendix II}

WOMAC index

$\mathbf{J} \quad \mathbf{L L}_{\mathrm{Lij}}$

0: Not any.

1: A little.

ا 1 - قليلة.

2: Moderate.

r- r- متوبطة.

3: Important.

r- كبيرة.

4: Very important - extreme.

\section{P Subscale:}

How much pain do you have:

ما هى شدة الآوجاع التى تحس بها؟

1: Walking on flat surface.

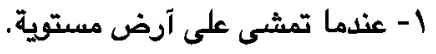

2: Going up or down stairs.

r- عندما تصعد آو تنزل الدرج.

3: At night while in bed.

r- في الليل وآنت فى فراثك.

4: Sitting or lying.

5: Standing upright.

ع- عند الجلوبس آو الإستلقاء.

ه- عند الوقوف.

S Subscale:

How severe is your stiffness:

1: After first wakening in the morning.

2: After sitting lying or resting later in the day.

\section{PF subscale:}

What degree of difficulty do you have:

1: Descending stairs.

2: Ascending stairs.

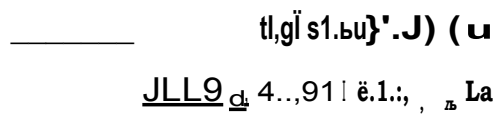

3: Rising from sitting.

4: Standing.

5: Bending to floor.

6: Walking on flat.

7: Getting in/out of car.

8: Going shopping.

9: Putting on socks/stockings.

10: Rising from bed.

11: Taking off socks/stockings.

12: Lying in bed.

13: Getting in/off bath.

14: Sitting.

15: Getting on/off toilet.

16: Heavy domestic duties.

„H , -^

:sV.a11ıg11 slsşy

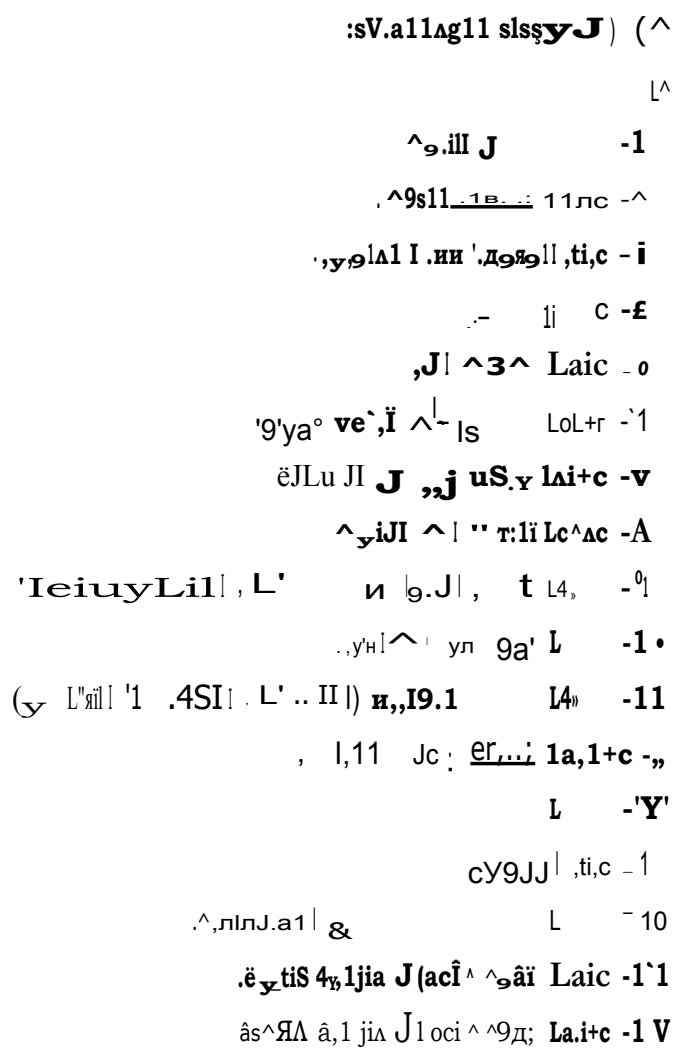

17: Light domestic duties.

Annex 1. English and Arab versions of WOMAC index. 